\title{
Patients' satisfaction with diabetes medications in one hospital, Saudi Arabia
}

\author{
This article was published in the following Dove Press journal: \\ Patient Preference and Adherence \\ II October 2012 \\ Number of times this article has been viewed
}

\author{
Shiekha Al-Aujan' \\ Sinaa Al-Aqeel' \\ Abdulhaleem Al-Harbi ${ }^{2}$ \\ Emad Al-Abdulltif ${ }^{2}$ \\ 'Clinical Pharmacy Department, \\ College of Pharmacy, King Saud \\ University, Riyadh, Saudi Arabia; \\ ${ }^{2}$ Department of Family Medicine, \\ Security Forces Hospital, Riyadh, \\ Saudi Arabia
}

Correspondence: Sinaa Al-Aqeel PO Box 3763I6, Riyadh II335,

Saudi Arabia

Tel +96650610 8592

Fax+966 I29I 3797

Email salageel@ksu.edu.sa
Objectives: The main aim of this study was to evaluate diabetic patients' satisfaction with their treatment. A secondary objective was to assess the relationship between treatment satisfaction scores and patient-related factors, if any.

Methods: This cross-sectional study collected data from patients at a primary care clinic of a government hospital located in Riyadh, the capital of Saudi Arabia. Patients were recruited if they were $\geq 18$ years of age, had type 2 diabetes, currently taking oral hypoglycemic agents or insulin or both, and able to read and write in Arabic. Satisfaction was measured using the Diabetes Medication Satisfaction (DiabMedSat) questionnaire.

Results: One hundred and twenty-three patients completed the questionnaire. The participant mean age was 46 years (standard deviation $[\mathrm{SD}]=11.2$ years; range $18-75$ years), and mean duration of the disease was 7.8 years ( $\mathrm{SD}=6.9$ years). Over half of respondents $(63 \%)$ reported that they were satisfied and only $16 \%$ were unsatisfied. Approximately $54 \%$ of respondents are interested in changing their diabetes medications. The overall satisfaction score was 59.56 ( $\mathrm{SD}=15.9)$. Mean scores for the burden, efficacy, and symptoms domains were 59.81 ( $\mathrm{SD}=15.7), 58.1(\mathrm{SD}=22.6)$, and $60.77(\mathrm{SD}=22.1)$, respectively. Treatment factors (eg, type of medication; $P<0.02$ ) and adherence factors (eg, difficulty taking medications; $P<0.032$ ) were independently associated with lower treatment satisfaction.

Conclusion: Diabetes patients with difficulties in adherence to recommendations, as well as patients treated with insulin, require more attention in order to improve their treatment satisfaction.

Keywords: diabetes mellitus, health status, patient satisfaction, primary health care, quality of health care

\section{Introduction}

Diabetes is a common disease in Saudi Arabia with a prevalence rate of $30 \% .{ }^{1}$ Diabetes is a chronic disease that requires continuing management, often including medication, to prevent acute complications and to reduce the risk of long-term complications. ${ }^{2}$ Given the ever increasing range of treatment options for diabetes, understanding treatment satisfaction for diabetes is especially important. ${ }^{3}$ Treatment satisfaction is one example of patient-reported outcomes. ${ }^{4}$ Patient-reported outcome has been defined as any report coming from patients about a health condition and its treatment. ${ }^{5}$ Measurement of treatment satisfaction is important, as greater satisfaction has been found to be associated with higher rates of adherence and compliance with treatment regimens. ${ }^{6,7}$ In diabetes, it has been shown that increased treatment satisfaction is 
associated with better glycemic control, ${ }^{8,9}$ suggesting that higher satisfaction is related to better clinical outcomes.

Former studies have measured factors that influence diabetes treatment satisfaction. Brod et al found that lower treatment satisfaction was associated with comorbidity, hypoglycemia, and weight gain. ${ }^{8}$ Nicolucci et al found that lower treatment satisfaction was associated with being female, using insulin, and having diabetes complications. ${ }^{9}$ They also found that treatment satisfaction and health-related quality of life are associated with each other. Other researchers noted that patients with hypoglycemia reported significant decreases in treatment satisfaction and lower quality of life, and higher levels of health care resource utilization. ${ }^{10,11}$ Biderman et al found that treatment satisfaction is significantly different between drug treatment options, as insulin-treated patients are least satisfied with treatment. ${ }^{12}$

The main aim of this study was to evaluate diabetic patients' satisfaction with their treatment. A secondary objective was to assess the relationship between treatment satisfaction scores and patient-related factors, if any.

\section{Methods}

This was a cross-sectional study conducted at a primary care clinic of a government hospital located in Riyadh, the capital of Saudi Arabia. The hospital has over 500 beds and provides services to Ministry of Interior personnel and their families.

\section{Study population}

Patients with electronic prescriptions of antidiabetic medication were identified upon their visit to the outpatient pharmacy to dispense their prescription. Patients were recruited if they were $\geq 18$ years of age, had type 2 diabetes, currently taking oral hypoglycemic agents, insulin, or both, and able to read and write in Arabic.

Before starting data collection, the study protocol had passed through the Research and Ethical Committee at the study site and the approval to proceed with this study was obtained. Patients were provided with information on the goals and methods of the study and verbal consent was obtained from each patient who volunteered to participate.

A pilot study was conducted over 1 week from (May 29June 2, 2010) and eight patients were recruited (one patient declined, and one did not complete the questionnaire). The study was conducted over 2 months (August and September 2010). The sample size was not calculated, but all eligible patients who visited the outpatient pharmacy during the study period were invited to participate in the study.

\section{Treatment satisfaction}

A self-administered Diabetes Medication Satisfaction (DiabMedSat) ${ }^{13}$ questionnaire was used to measure satisfaction. The DiabMedSat is designed to assess treatment satisfaction in persons with both type 1 and type 2 diabetes mellitus and across multiple treatment modalities (oral, syringe, or pen). The DiabMedSat has 22 items, assessing three treatment satisfaction domains: efficacy, treatment burden (frequency of monitoring blood glucose and medication dosing), and symptoms (side effects), each of which is computed as a score. In addition, a total satisfaction score is computed. Each item in the scale uses a five- to seven-point Likert scale; overall and domain scores range from zero to 100, with higher scores indicating greater levels of treatment satisfaction.

DiabMedSat has been translated into many languages, including Arabic for another country. This Arabic version was written in the Modern Standard Arabic or the literary Arabic. The literary Arabic language is more widely used in the Arab World unlike the dialectal Arabic. The dialectal Arabic refers to the many national or regional varieties which constitute the everyday spoken Arabic language. However, these varieties are typically not used for written or formal communications. Instead, the literary Arabic is used in printed publications, spoken by the Arabic media, and understood by most educated Arabic speakers. For this reason, we used the available Arabic version without performing forward and backward translations. We did, however, subject it to a patient-testing stage $(n=7)$ and it did not reveal any conceptual problems. The questionnaire was well accepted. A user agreement was signed with MAPI Research Institute (Lyon, France) prior to using the Arabic questionnaire.

\section{Adherence}

Seven questions related to adherence included difficulty in changing dietary habits, in changing physical habits, in taking medication, in attending follow-up visits, owning a blood glucose meter, using the meter, and frequency of selfmonitoring of blood glucose. These questions were adapted from Biderman et al. ${ }^{12}$

\section{Sociodemographic parameters and clinical data}

Data regarding age, sex, marital status, education, and presence of comorbidities were collected from the patients. Other information related to clinical parameters, such as hemoglobin $\mathrm{A}_{1 \mathrm{c}}\left(\mathrm{HbA}_{1 \mathrm{c}}\right)$ was collected from patients' electronic medical records. 


\section{Questionnaire administration}

Patients completed the questionnaire while waiting for their medications to be prepared at the primary care clinic outpatient pharmacy and incentives were given for each patient that returned the questionnaire. A form was used by the researcher to document the number of patients approached and medical record numbers of those who agreed to participate to ensure that patients who were given the survey returned it and were not invited to the study again.

\section{Data management and analysis}

The DiabMedSat scoring algorithms allow subjects to miss two items in burden, one item in efficacy, and one item in symptoms and still have subscale scores. Questionnaires were excluded if they exceeded the permitted number of missing items in the questionnaire. One of the authors (AS) entered the data from all surveys. A random check was conducted of all data entered. Results of the survey were evaluated using SPSS version 15.0 (IBM Corporation, Armonk, NY).

Categorical data is presented as percentages of frequency and continuous data reported as means with standard deviations (SD). The relationship between satisfaction (mean scores of DiabMedSat) and the following variables were investigated: gender, marital status, education, employment status, type of diabetes treatment (oral agents, insulin, or both), diabetes duration, complications, comorbid conditions, and self-monitoring of blood glucose. Two-tailed $t$-tests were used to compare satisfaction between two groups, while one-way analysis of variance was used to compare means across three or more groups. The correlations between continuous variables such as age, $\mathrm{HbA}_{1 \mathrm{c}}$ levels, and treatment satisfaction were tested by Pearson analysis. Statistical significance was determined at $P<0.05$.

\section{Results}

\section{Sample description}

One hundred and eighty-seven patients agreed to participate in the study. Twelve patients were excluded (seven illiterate, two newly diagnosed with diabetes and had no experience with medications, three on diet only). One hundred and sixty-eight patients returned the questionnaire. Forty-five patients were excluded because they exceeded the permitted number of missing items in the questionnaire. The final sample was 123 patients. The respondents' mean age was 46 years ( $\mathrm{SD}=11.2$ years; range $18-75$ years), and mean duration of the disease was 7.8 years ( $\mathrm{SD}=6.9$ years). The respondents' mean $\mathrm{HbA}_{1 \mathrm{c}}$ level was $8.57 \%$ ( $\left.\mathrm{SD}=2.05 \%\right)$. Twenty-nine patients $(23.6 \%)$ had $\mathrm{HbA}_{1 \mathrm{c}}$ level of $\leq 7 \%$. Ninety-three $(76 \%)$
Table I Demographic and clinical characteristics $(N=123)$

\begin{tabular}{|c|c|c|}
\hline Patient characteristics & $\mathbf{n}$ & $\%$ \\
\hline \multicolumn{3}{|l|}{ Sex } \\
\hline Male & 51 & 41.5 \\
\hline Female & 72 & 58.5 \\
\hline \multicolumn{3}{|l|}{ Marital status $^{\mathrm{a}}$} \\
\hline Single & 5 & 4.1 \\
\hline Married & 100 & 81.3 \\
\hline Divorced/widowed & 16 & 13.0 \\
\hline \multicolumn{3}{|l|}{ Education $^{\mathrm{a}}$} \\
\hline Read and write & 15 & 12.2 \\
\hline Primary school & 23 & 18.7 \\
\hline Intermediate school & 18 & 14.6 \\
\hline High school & 31 & 25.2 \\
\hline College & 22 & 17.9 \\
\hline \multicolumn{3}{|l|}{ Work status ${ }^{a}$} \\
\hline Working & 47 & 38.2 \\
\hline Not working & 74 & 60.2 \\
\hline \multicolumn{3}{|l|}{ Salary (Saudi Riyals) ${ }^{a}$} \\
\hline$<4500$ & 36 & 29.3 \\
\hline $4500-5999$ & 11 & 8.9 \\
\hline $6000-9000$ & 17 & 13.8 \\
\hline$>9000$ & 34 & 27.6 \\
\hline \multicolumn{3}{|l|}{$H_{b} A_{I c}{ }^{a}$} \\
\hline$\leq 7 \%$ & 29 & 23.6 \\
\hline $7.1 \%-8 \%$ & 29 & 23.6 \\
\hline $8.1 \%-9 \%$ & 16 & 13.0 \\
\hline$>9 \%$ & 42 & 34.1 \\
\hline \multicolumn{3}{|l|}{ Comorbidities $^{\mathrm{b}}$} \\
\hline Hypertension & 52 & 42.3 \\
\hline Heart disease & 2 & 1.6 \\
\hline Dyslipidemia & 78 & 63.4 \\
\hline Other diseases & 5 & 4.1 \\
\hline No comorbidities & 30 & 24.4 \\
\hline \multicolumn{3}{|l|}{ Complications $^{\mathrm{b}}$} \\
\hline Neuropathy & 14 & 11.4 \\
\hline Nephropathy & 2 & 1.6 \\
\hline Ocular & 47 & 38.2 \\
\hline Diabetic foot & 8 & 6.5 \\
\hline No complications & 61 & 49.6 \\
\hline \multicolumn{3}{|l|}{ Type of treatment } \\
\hline OAD & 82 & 66.7 \\
\hline Insulin & 9 & 7.3 \\
\hline OAD and insulin & 32 & 26 \\
\hline \multicolumn{3}{|l|}{ Insulin delivery device } \\
\hline Injection & 32 & 78 \\
\hline Pen & 9 & 22 \\
\hline \multicolumn{3}{|c|}{ Number of OADs/patient } \\
\hline One oral & 41 & 35.9 \\
\hline Two orals & 60 & 52.6 \\
\hline Three orals and more & 13 & 11.4 \\
\hline \multicolumn{3}{|c|}{ Number of insulin/patient ${ }^{a}$} \\
\hline One type & 33 & 80.5 \\
\hline Two types & 7 & 17.0 \\
\hline \multicolumn{3}{|l|}{ Injection frequency } \\
\hline Once daily & 10 & 24.4 \\
\hline Twice daily & 28 & 68.3 \\
\hline Three times daily & 3 & 7.3 \\
\hline
\end{tabular}


Table I (Continued)

\begin{tabular}{lll}
\hline Patient characteristics & $\mathbf{n}$ & $\%$ \\
\hline Able to adjust insulin dose & \\
Yes & & \\
No & 24 & 58.5 \\
Type of medication & 15 & 36.5 \\
OAD & & \\
Acarbose & 13 & 10.5 \\
Metformin & 107 & 86.9 \\
Sulfonylurea & 64 & 52 \\
Pioglitazone & 13 & 10.5 \\
Insulin & & \\
Aspart & 1 & 0.8 \\
Regular & 6 & 4.9 \\
NPH & 8 & 6.5 \\
Mixtard 70/30 & 25 & 20.3 \\
Glargine & 7 & 5.7 \\
\hline
\end{tabular}

Notes: ${ }^{a}$ The number is less than expected because of missing data; ${ }^{b}$ the number is more than expected because some respondents may have had more than one answer. Abbreviations: $\mathrm{HbA}_{1 \mathrm{c}}$, hemoglobin $\mathrm{A}_{\mathrm{Ic}} ; \mathrm{NPH}$, neutral protamine Hagedorn; OAD, oral antidiabetic drug; $\mathrm{SD}$, standard deviation.

respondents reported having comorbidities and 53 (43\%) reported having complications. The majority were on oral hypoglycemic agents alone (66.7\%). The sociodemographic and clinical characteristics of respondents are shown in Table 1.

\section{Treatment satisfaction}

Over half of respondents $(63 \%)$ reported they were satisfied and only $16 \%$ were unsatisfied (Table 2). Interestingly, however, that $54 \%$ of them were interested in changing their diabetes medications (Table 2). The overall satisfaction score was $59.56(\mathrm{SD}=15.9)$. Mean scores for the burden, efficacy, and symptoms domains were $59.81(\mathrm{SD}=15.7)$, $58.1(\mathrm{SD}=22.6)$, and $60.77(\mathrm{SD}=22.1)$, respectively.

\section{Relationship between satisfaction, clinical parameters, and sociodemographics}

There was no relationship between satisfaction score and $\mathrm{HbA}_{1 \mathrm{c}}(\mathrm{r}=0.03, P=0.72)$, age $(\mathrm{r}=0.114, P=0.215)$, or years with diabetes $(\mathrm{r}=-0.028, P=0.76)$. No association was found between treatment satisfaction and sex, complication, comorbidity, owning a glucose meter, or using it (Tables 3 and 4).

There was a statistically significant relationship between total satisfaction score and type of medication, where insulin users had lower satisfaction scores than those who were receiving oral medications (Table 3). Satisfied patients were more adherent in taking their medications, changing their dietary habits, performing physical activities, and attending their follow-up visits (Table 4).

\section{Discussion}

\section{Treatment satisfaction}

Results from this survey indicate that diabetes patients were moderately satisfied with their current therapy and were interested in trying new therapeutic options, leaving substantial room for improvement.

The results of the current study also suggest that insulintreated patients are the least satisfied with treatment. This is in concordance with the findings of others. ${ }^{9}{ }^{12}$ This could be related to the fact that injecting insulin is less comfortable than taking a pill. Another possible explanation is that insulintreated patients have a longer disease duration with more complications. Also, lower satisfaction scores may reflect patients' perception that insulin treatment means that their health status has deteriorated. ${ }^{12}$

Several studies have reported that the presence of complications affects satisfaction in diabetes patients..$^{9,12}$ In the current study, the satisfaction scores were higher in patients with no complications, but this was not statistically significant $(P=0.052)$. This is likely due to the small sample size.

In agreement with previous research, ${ }^{6,12}$ this study found that satisfied patients are more adherent to recommendations regarding dietary habits, physical activity, medications use, and follow-up visits.

Table 2 Respondents' overall treatment satisfaction and interest to change their diabetes medication

\begin{tabular}{|c|c|c|c|c|c|c|}
\hline \multicolumn{7}{|c|}{$\begin{array}{l}\text { Overall, thinking about each aspect of your dia } \\
\text { been with your current diabetes medications? }\end{array}$} \\
\hline $\begin{array}{l}\text { Extremely } \\
\text { dissatisfied }\end{array}$ & $\begin{array}{l}\text { Very } \\
\text { dissatisfied }\end{array}$ & $\begin{array}{l}\text { Slightly } \\
\text { dissatisfied }\end{array}$ & Neither & $\begin{array}{l}\text { Slightly } \\
\text { satisfied }\end{array}$ & $\begin{array}{l}\text { Very } \\
\text { satisfied }\end{array}$ & $\begin{array}{l}\text { Extremely } \\
\text { satisfied }\end{array}$ \\
\hline $2(2)$ & $4(3)$ & $14(11)$ & $26(2 \mathrm{I})$ & $20(16)$ & $33(27)$ & $24(20)$ \\
\hline \multicolumn{7}{|c|}{$\begin{array}{l}\text { Overall, based on your current experience with your diabetes medications, how INTERESTED would you be to change the type of } \\
\text { medications you take or the way you take it, if it was possible? }\end{array}$} \\
\hline $\begin{array}{l}\text { Not at all } \\
\text { interested }\end{array}$ & \multicolumn{2}{|c|}{$\begin{array}{l}\text { Slightly } \\
\text { interested }\end{array}$} & $\begin{array}{l}\text { Somewhat } \\
\text { interested }\end{array}$ & \multicolumn{2}{|c|}{$\begin{array}{l}\text { Very } \\
\text { interested }\end{array}$} & $\begin{array}{l}\text { Extremely } \\
\text { interested }\end{array}$ \\
\hline $13(11)$ & \multicolumn{2}{|c|}{$18(15)$} & $25(20)$ & \multicolumn{2}{|c|}{$37(30)$} & $30(24)$ \\
\hline
\end{tabular}

Note: Data represents $n(\%)$. 
Table 3 Relationship between treatment satisfaction score with sex, diabetes treatment modalities, complications

\begin{tabular}{|c|c|c|c|}
\hline & $\mathbf{n}$ & $\begin{array}{l}\text { Satisfaction } \\
\text { mean score (SD) }\end{array}$ & $P$ value \\
\hline \multicolumn{4}{|l|}{ Sex } \\
\hline Male & 51 & $62.1(15.4)$ & $0.133^{\mathrm{a}}$ \\
\hline Female & 72 & $57.7(16.2)$ & \\
\hline \multicolumn{4}{|c|}{ Type of treatment (general) } \\
\hline Oral & 82 & $62.4(15.7)$ & $0.02^{b}$ \\
\hline Insulin & 9 & $52.9(15.0)$ & \\
\hline Both & 32 & $54.1(15.5)$ & \\
\hline \multicolumn{4}{|c|}{ Complications } \\
\hline Yes & 53 & $56.5(16.6)$ & $0.052^{\mathrm{a}}$ \\
\hline No & 61 & $62.5(15.5)$ & \\
\hline \multicolumn{4}{|c|}{ Comorbidities } \\
\hline Yes & 93 & $59.2(17.0)$ & $0.73^{\mathrm{a}}$ \\
\hline No & 30 & $60.4(14.5)$ & \\
\hline
\end{tabular}

Notes: alndependent $t$-test; banalysis of variance.

Abbreviation: SD, standard deviation.

\section{Implications for practice}

Patient-reported measures can help clinicians target interventions that will improve patient outcomes of care. ${ }^{4}$ Based on the results of the current study, it seems important to provide support for nonsatisfied patients to improve their adherence, and thus have a positive influence on their clinical outcomes. Addressing misconceptions about insulin therapy during patient counseling may improve treatment satisfaction. Recognizing and addressing the issue of complications in

Table 4 Relationship between treatment satisfaction scores and adherence

\begin{tabular}{|c|c|c|c|}
\hline & $\mathbf{n}$ & $\begin{array}{l}\text { Satisfaction } \\
\text { mean score (SD) }\end{array}$ & $P$ value $^{a}$ \\
\hline \multicolumn{4}{|c|}{ Find difficulty changing dietary habits } \\
\hline Yes & 76 & $54.6(14.7)$ & 0.000 \\
\hline No & 44 & $67.9(15.0)$ & \\
\hline \multicolumn{4}{|c|}{ Find difficulty changing physical activity } \\
\hline Yes & 65 & $54.8(15.2)$ & 0.000 \\
\hline No & 53 & $65.1(15.6)$ & \\
\hline \multicolumn{4}{|c|}{ Find difficulty taking medications } \\
\hline Yes & 31 & $54.3(13.9)$ & 0.032 \\
\hline No & 87 & $61.5(16.5)$ & \\
\hline \multicolumn{4}{|c|}{ Find difficulty attending follow-up visits } \\
\hline Yes & 44 & $52.2(14.9)$ & 0.000 \\
\hline No & 72 & $64.0(15.5)$ & \\
\hline \multicolumn{4}{|c|}{ Own a blood glucose meter } \\
\hline Yes & 86 & $60.3(15.7)$ & 0.650 \\
\hline No & 35 & $58.8(16.3)$ & \\
\hline \multicolumn{4}{|c|}{ Use the blood glucose meter } \\
\hline Yes & 79 & $60.0(16.4)$ & 0.841 \\
\hline No & 38 & $60.6(15.0)$ & \\
\hline
\end{tabular}

Note: andependent $t$-test.

Abbreviation: SD, standard deviation. diabetes patients through individually structured patient education programs could decrease the intolerance of these issues, and thereby may improve patient outcomes through higher medication adherence and greater treatment satisfaction levels. This necessitates a multidisciplinary team care approach where physicians, nurses, pharmacists, dieticians, and physiotherapists all collaborate in providing care for diabetic patients.

\section{Limitations and future directions}

Research on patient-related outcomes measures is in its infancy in Saudi Arabia, and the present report is the first on patient satisfaction with their medications in Saudi diabetic patients. However, the current results should be considered within the context of several limitations. The sample size was small with many participants being relatively young with no complications. Further scientific studies including larger data sets or even national data from Saudi may shed more light on this topic. The study design was cross-sectional, thus it cannot be concluded whether treatment satisfaction was influenced by the different independent variables or vice versa. Future research using a prospective design with a larger sample size should be conducted to obtain a more comprehensive analysis of treatment satisfaction among a diabetes population. Other parameters such as depression, anxiety, and quality of life, which might affect patient satisfaction, were not addressed in this study. This also requires further investigation. The study was conducted in one primary care clinic in Riyadh; therefore the findings may not be generalized to other health care centers, settings, or geographic regions. The results are also limited by reliance upon the participants' self-reports and not upon objective clinical data, with the possibility of recall bias. Also, incentives given to the patients and how it influenced their response is unclear.

\section{Conclusion}

Diabetes patients with difficulties in adherence to recommendations, as well as patients treated with insulin, require more attention in order to improve their treatment satisfaction.

\section{Acknowledgments}

The authors thank the Research Center at the Female Center for Scientific and Medical Colleges, King Saud University for their financial support towards the publication of this paper.

\section{Disclosure}

The authors report no conflicts of interest in this work. 


\section{References}

1. Alqurashi KA, Aljabri KS, Bokhari SA. Prevalence of diabetes mellitus in a Saudi community. Ann Saudi Med. 2011;31(1):19-23.

2. American Diabetes Association. Standards of medical care in diabetes: 2012. Diabetes Care. 2012;35(Supp1 1):S11-S63.

3. Testa M. Improving diabetes therapy: improving satisfaction. Diabetes Voice. 2003;48(4):23-25.

4. Lohr KN, Zebrack BJ. Using patient-reported outcomes in clinical practice: challenges and opportunities. Qual Life Res. 2009;18(1):99-107.

5. United States Department of Health and Human Services Food and Drug Administration; Center for Drug Evaluation and Research; Center for Biologics Evaluation and Research; Center for Devices and Radiological Health. Guidance for industry: patient-reported outcome measures: use in medical product development to support labeling claims: draft guidance. Health Qual Life Outcomes. 2006;4:79.

6. Barbosa CD, Balp MM, Kulich K, Germain N, Rofail D. A literature review to explore the link between treatment satisfaction and adherence, compliance, and persistence. Patient Prefer Adherence. 2012;6: 39-48.

7. Atkinson MJ, Kumar R, Cappelleri JC, Hass SL. Hierarchical construct validity of the Treatment Satisfaction Questionnaire for Medication (TSQM Version II) among outpatient pharmacy consumers. Value Health. 2005;8(Suppl 1):S9-S24.
8. Brod M, Valensi P, Shaban JA, Bushnell DM, Christensen TL. Patient treatment satisfaction after switching to NovoMix ${ }^{\circledR} 30$ (BIAsp 30) in the IMPROVE ${ }^{\mathrm{TM}}$ study: an analysis of the influence of prior and current treatment factors. Qual Life Res. 2010;19(9):1285-1293.

9. Nicolucci A, Cucinotta D, Squatrito S, et al. Clinical and socio-economic correlates of quality of life and treatment satisfaction in patient with type 2 diabetes. Nutr Metab Cardiovasc Dis. 2009;19(1):45-53.

10. Pollack MF, Purayidathil FW, Bolge SC, Williams SA. Patient-reported tolerability issues with oral antidiabetic agents: associations with adherence, treatment satisfaction and health-related quality of life. Diabetes Res Clin Pract. 2010;87(2):204-210.

11. Williams SA, Pollack MF, DiBonaventura M. Effects of hypoglycemia on health-related quality of life, treatment satisfaction and healthcare resource utilization in patients with type 2 diabetes mellitus. Diabetes Res Clin Pract. 2011;91(3):363-370.

12. Biderman A, Noff E, Harris SB, Friedman N, Levy A. Treatment satisfaction of diabetic patients: what are the contributing factors? Fam Pract. 2009;26(2):102-108.

13. Brod M, Skovlund SE, Wittrup-Jensen KU. Measuring the impact of diabetes through patient report of treatment satisfaction, productivity and symptom experience. Qual Life Res. 2006;15(3):481-491.
Patient Preference and Adherence

\section{Publish your work in this journal}

Patient Preference and Adherence is an international, peer-reviewed, open access journal focusing on the growing importance of patient preference and adherence throughout the therapeutic continuum. Patient satisfaction, acceptability, quality of life, compliance, persistence and their role in developing new therapeutic modalities and compounds to

\section{Dovepress}

optimize clinical outcomes for existing disease states are major areas of interest. This journal has been accepted for indexing on PubMed Central. The manuscript management system is completely online and includes a very quick and fair peer-review system. Visit http://www.dovepress.com/ testimonials.php to read real quotes from published authors. 